\title{
Política habitacional no Brasil: uma análise das coalizões de defesa do Sistema Nacional de Habitação de Interesse Social versus o Programa Minha Casa, Minha Vida
}

\author{
Housing policy in Brazil: an advocacy coalition analysis of the National Social Interest \\ Housing System versus Minha Casa, Minha Vida Program
}

Geniana Gazotto Ferreira[a], Paulo Calmon[a], Antônio Sérgio Araújo Fernandes ${ }^{[b]}$,

Suely Mara Vaz Guimarães de Araújo[a,c]

\author{
[a] Universidade de Brasília (UnB), Instituto de Ciência Política, Brasília, DF, Brasil \\ [b] Universidade Federal da Bahia (UFBA), Escola de Administração, Salvador, BA, Brasil \\ [c] Instituto Brasiliense de Direito Público (IDP), Brasília, DF, Brasil
}

Como citar: Ferreira, G. G., Calmon, P., Fernandes, A. S. A., \& Araújo, S. M. V. G. (2019). Política habitacional no Brasil: uma análise das coalizões de defesa do Sistema Nacional de Habitação de Interesse Social versus o Programa Minha Casa, Minha Vida. urbe. Revista Brasileira de Gestão Urbana, 11, e20180012. https://doi.org/10.1590/21753369.011.001.A004

\section{Resumo}

Este artigo analisa mudanças institucionais ocorridas na política de habitação no Brasil entre 1992 a 2014, a partir da análise de Advocacy Coalition Framework, que fornece subsídios para compreender quais são os valores e as ideias presentes na formulação e na alteração do Sistema Nacional de Habitação de Interesse Social (SNHIS) e do Programa Minha Casa, Minha Vida (PMCMV). A pesquisa utiliza dados coletados de leis, normas, atas do Conselho e das Conferências Nacionais das Cidades, notas de audiência pública e entrevistas. Por meio desses documentos, foi realizada análise da Lei no 11.124/2005, que tramitou durante 13 anos no Congresso Nacional até ser aprovada. Essa Lei criou o SNHIS, estabeleceu o processo participativo de elaboração do Plano Nacional de Habitação e constituição de fundos articulados nos diferentes níveis da federação. Entretanto, o governo federal, em 2009, por Medida Provisória, adotou uma alternativa ao SNHIS com a criação do PMCMV, que tramitou em caráter de urgência e foi aprovada em menos de quatro meses, sendo convertida na Lei $\mathrm{n}^{\circ}$ 11.977/2009. O estudo possibilitou entendimento crítico do processo de discussão e elaboração das leis, concluindo que as mudanças institucionais realizadas priorizaram mais os objetivos de mercado do que os objetivos de desenvolvimento urbano integrado.

Palavras-chave: Sistema Nacional de Habitação de Interesse Social. Programa Minha Casa, Minha Vida. Modelo de coalizões de defesa.

\section{Abstract}

This article analyzes the institutional changes in the housing policy in Brazil from 1992 to 2014, based on the Advocacy Coalition Framework, which provides insights to understand the values and ideas present in the formulation and modification of the National Social Interest Housing System (SNHIS) and

GGF é doutoranda, e-mail: genianagazotto@gmail.com

PC é doutor, e-mail: paulo.calmon@gmail.com

ASAF é doutor, e-mail: antoniosergio07@gmail.com

SMVGA é doutora, e-mail: suelymvg@gmail.com 
Minha Casa, Minha Vida Program (MCMVP). The methods included data from laws, rules and minutes from National Council and Conference of Cities, public hearings, and interviews. Through these documents, we analyzed the Law $n^{\circ} 11124 / 2005$, which remained in debate in the National Congress for 13 years before it became law. This law created the SNHIS, established the participatory approach for housing plan formulation, and for the establishment of funds at the three levels of government, which are controlled by popular councils. However, in 2009 the federal government adopted an alternative to SNHIS and created, through a provisional act, the MCMVP. The bill was certified as urgent by the National Congress and approved in less than four months before becoming Law no 11977/2009. The present study suggests a critical understanding of policy-making processes and concludes that the institutional changes made tended to protect the market interests, with little regard for integrated urban planning.

Keywords: National Social Interest Housing System. Minha Casa, Minha Vida Program. Advocacy coalition framework.

\section{Introdução}

Desde a redemocratização, concomitante com a crise do Sistema Financeiro de Habitação e a consequente extinção do Banco Nacional de Habitação (BNH) em 1986, ocorreu redução significativa de recursos federais que eram disponibilizados para investimento na área habitacional. Com a Constituição de 1988, foram estabelecidas as competências entre os níveis de governo no que se refere tanto à política urbana quanto à promoção de programas de construção de moradias e à melhoria das condições habitacionais e de saneamento básico. A responsabilidade sobre tais matérias, portanto, passou a ser compartilhada entre os entes federativos, ou seja, os programas ligados à área urbana, sobretudo no que tange à habitação, tornaram-se fragmentados em secretarias de governos subnacionais que se reestruturavam ou desapareciam de acordo com as mudanças partidárias na gestão pública (Maricato, 2009; Azevedo \& Andrade, 2011).

Após a regulamentação dos artigos 182 e 183 da Constituição Federal de 1988, por meio da Lei no 10.257/2001, denominada Estatuto da Cidade, foram estabelecidas diretrizes gerais da política urbana, tendo como uma de suas finalidades reverter a segregação espacial presente na maioria das cidades brasileiras. Avançando no que o Estatuto da Cidade estabeleceu, em 2005 foi aprovada a Lei no 11.124, que criou o Sistema Nacional de Habitação de Interesse Social (SNHIS), lei que tramitou durante 13 anos no Congresso Nacional até ser aprovada e que estabeleceu o processo participativo de elaboração do Plano Nacional de Habitação e constituição de fundos articulados nos diferentes níveis da federação, controlados por conselhos com participação popular e com ações planejadas em Planos Locais de Habitação de Interesse Social.

A partir da criação do SNHIS, instituído por lei de iniciativa popular que contou com intensa discussão entre os atores envolvidos, esperava-se que a política habitacional tomasse o caminho estabelecido para sua execução, algo que não ocorreu - isso se demonstra na dificuldade de a matéria entrar com vinculação orçamentária por meio de Proposta de Emenda Constitucional (PEC). Nesse período, o que se observou por parte do governo federal foi a adoção de uma alternativa no que se refere à política habitacional desenhada pelo SNHIS, com a criação do Programa Minha Casa, Minha Vida (PMCMV), um novo programa de habitação concebido como forma de aquecer a economia para enfrentar a crise financeira mundial que tinha repercussões no Brasil e para assegurar um ganho político de curto prazo para a coalizão político-partidária do governo, que visava à continuidade de sua administração.

O Programa Minha Casa, Minha Vida tem como principal objetivo a redução do déficit habitacional ao criar mecanismos de incentivo à produção e à aquisição de novas unidades habitacionais, à requalificação de imóveis urbanos e à produção ou à reforma de habitações rurais para famílias com renda mensal de até dez salários mínimos. Com essa iniciativa, o governo buscou garantir acesso da 
população de baixa renda à casa própria e influenciar o crescimento econômico com a geração de empregos. Entretanto, para criar o PMCMV, o governo federal necessitou fazer barganhas e articulações políticas que permitiram que o processo tramitasse em regime de urgência e que a lei fosse aprovada com celeridade. Devido às barganhas e às negociações políticas, tanto o Plano Nacional de Desenvolvimento Urbano quanto a Política Nacional de Habitação foram subjugados às negociações do mercado.

Este artigo traz como perguntas: quais foram as principais mudanças institucionais ocorridas na política pública de habitação no Brasil no período de 1992 a 2014? E por que essas mudanças ocorreram?

Para responder a essas questões, o artigo analisa os atores e as coalizões na política habitacional a partir do modelo de Advocacy Coalition Framework, visando fornecer subsídios para compreender quais foram os valores e as ideias presentes na formulação do Sistema Nacional de Habitação de Interesse Social e do Programa Minha Casa, Minha Vida. Para atingir esse objetivo, serão observadas as mudanças institucionais na política habitacional brasileira no período de 1992 a 2014 e as principais consequências decorrentes das inovações institucionais nas políticas de desenvolvimento urbano.

0 artigo está dividido em três partes, além desta introdução e uma seção de conclusão. A segunda parte apresenta o referencial de Advocacy Coalition Framework, como ele vem sendo tratado no caso das políticas públicas no Brasil e como metodologicamente será desenvolvido neste artigo, diante do objeto de estudo. A terceira parte aborda os dois programas, bem como o processo de formulação e as diferenças entre os dois programas de habitação (SNHIS e PMCMV). A quarta parte vai tratar de desenvolver a análise de como foi o processo de formação de coalizão nos dois casos.

\section{Advocacy Coalition Framework e o procedimento teórico-metodológico do trabalho}

\section{Advocacy Coalition Framework}

O Advocacy Coalition Framework (ACF), ou Modelo de Coalizões de Defesa (MCD), foi originalmente proposto por Sabatier e Jenkins-Smith na década de 1980 e, posteriormente, aperfeiçoado por Sabatier \& Weible (2007). O ACF procura compreender quais são os valores e as ideias necessários para formulação e alteração das políticas públicas em perspectivas temporais de uma década ou mais.

O ACF começou a receber atenção no Brasil a partir do ano 2000, configurando-se como um relevante modelo de análise de políticas públicas. As adaptações do modelo passaram a ser utilizadas em diversas pesquisas acadêmicas para o estudo de políticas de alcance nacional com a finalidade de analisar mudanças institucionais e aprendizado político em variadas áreas de conhecimento, tais como ciência política, sociologia, administração pública, serviço social, saúde pública, meio ambiente, tecnologia e inovação (Capelari et al., 2015).

As coalizões podem ser definidas como redes de atores que compartilham sistemas de crenças políticas e detêm determinados recursos, tais como conhecimento, recursos financeiros, mobilização da opinião pública, uso estratégico da informação, entre outros aspectos. Tal modelo pressupõe que ideias e valores, interligados nesses sistemas de crenças políticas, socializam os indivíduos em relação aos padrões de comportamento, estabelecendo estruturas de alianças e conflitos (Sabatier \& Weible, 2007). Para obter sucesso nos resultados, os atores formam alianças, compartilham recursos e desenvolvem estratégias complementares.

0 modelo assume que o processo político nas sociedades modernas é complexo, por isso os participantes precisam se especializar para obter influência. Os subsistemas são decorrentes da especialização e se caracterizam pelas dimensões substantiva, funcional e territorial. 0 modelo pressupõe que as informações técnicas e científicas têm um importante papel na elaboração de políticas 
públicas, portanto os pesquisadores são atores relevantes no processo de formulação da política pública (Sabatier \& Weible, 2007).

Esse modelo de análise se interessa pelas mudanças políticas em um universo temporal superior a uma década. Fatores como condições sociais, aspectos econômicos, opinião pública, mudanças nas coalizões governamentais e não governamentais, além das decisões relacionadas aos outros subsistemas, são mais suscetíveis a mudanças, especialmente no intervalo superior a dez anos (Sabatier \& Jenkins-Smith, 1999).

Além desse entendimento de que as mudanças no âmbito das políticas públicas necessitam ser analisadas em períodos longos, o modelo de Sabatier \& Jenkins-Smith (1999) também leva em consideração as seguintes premissas: reconhecimento da importância das informações técnicas nos processos de tomada de decisão das políticas; subsistemas como unidades de análise mais propícias para o estudo da mudança nas políticas públicas; participação de diversos conjuntos de atores nesses referidos subsistemas, tais como atores governamentais, consultores, cientistas, mídia e outros formadores de opinião; e também compreensão de que as políticas públicas podem ser analisadas como representações de sistema de crenças e valores dos atores participantes.

Esse sistema de crenças dos atores e das coalizões fundamenta a interpretação e o diagnóstico em relação aos fenômenos políticos. A estrutura do sistema de crenças pode ser decomposta em três níveis: núcleo duro (deep core), com postulados normativos e ontológicos fundamentais; núcleo político (policy core), com posições delimitadas em relação à determinada política pública, concernentes às estratégias básicas para atingir os valores do núcleo duro; e aspectos instrumentais (secondary aspects), com decisões instrumentais e informações necessárias para viabilizar o núcleo político (Sabatier \& JenkinsSmith, 1999). De acordo com os autores, tais níveis estão dispostos em uma hierarquia com grau crescente de permeabilidade a mudanças (Figura 1).

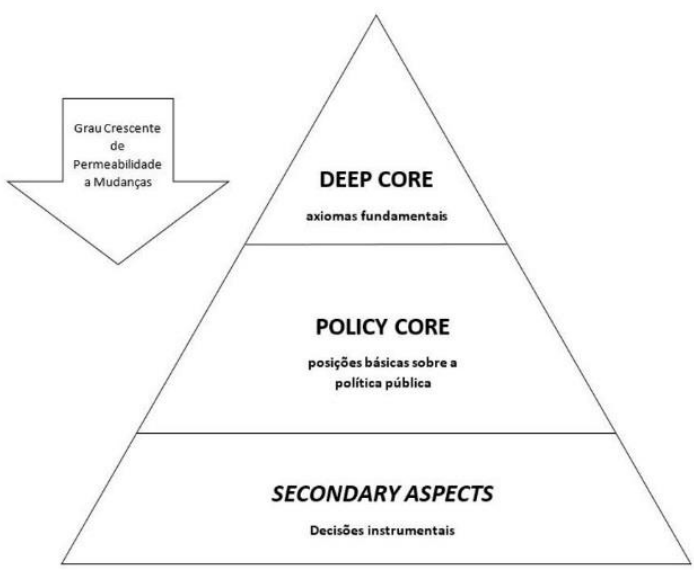

Figura 1 - Estrutura do sistema de crenças das coalizões. Fonte: Elaboração dos autores (2017).

No núcleo duro, estão os axiomas normativos e ontológicos fundamentais, ou seja, as crenças, que são difíceis de serem mudadas devido aos valores intrínsecos e à grande resistência dos atores. No núcleo político, estão os posicionamentos acerca das políticas públicas, referentes às estratégias básicas, às opções programáticas, aos conflitos e à teoria de ação para atingir os valores do núcleo duro. Mudanças de coalizões do núcleo político são geralmente decorrentes de fatores exógenos ao sistema. Já os aspectos instrumentais são as medidas necessárias para colocar em prática o núcleo político, e as mudanças nesse nível são mais acessíveis que nos outros níveis mencionados. As mudanças políticas na estrutura do sistema de crenças ocorrem por meio de aprendizado orientado às políticas públicas (policy-oriented learning), tais como os fatores cognitivos dentro e entre coalizões. Esse aprendizado tende a provocar uma alteração duradoura de pensamento ou de comportamento, que resulta da dinâmica dos debates e dos conflitos entre as coalizões. Tais aspectos são relevantes para a identificação e a análise de mudanças nas políticas públicas (Vicente \& Calmon, 2011). 


\section{Procedimentos metodológicos adotados no trabalho}

Esta pesquisa é um estudo de caso sobre a política habitacional federal à luz do Advocacy Coalition Framework. Trata-se de um estudo empírico e com caráter longitudinal sobre a formação e a atuação de coalizões no subsistema de habitação. Foram adotados variados procedimentos metodológicos, como o estudo da elaboração de leis, o acompanhamento de reuniões do Conselho das Cidades e de audiência pública na Câmara dos Deputados, a seleção de documentos do Conselho e das Conferências das Cidades, a realização de entrevistas, o desenvolvimento de um código de análise documental e a análise qualitativa dos resultados.

Foram enfatizados os estudos de duas leis especificamente: Lei no 11.124, de 16 de junho de 2005, e Lei no 11.977, de 7 de julho de 2009. A escolha dessas leis ocorreu por elas instituírem, respectivamente, os seguintes marcos do subsistema de habitação: o Sistema Nacional de Nacional de Habitação de Interesse Social e o Programa Minha Casa, Minha Vida. Considera-se que entre os processos decisórios, em relação aos quais se podem analisar os efeitos do sistema de crenças, estão os processos relacionados às leis.

Além da análise documental, foram realizadas entrevistas com atores que participaram do processo de formulação e implementação da política de habitação. A estratégia de seleção das entrevistas buscou manter a paridade de representantes, conforme previsto no Conselho e nas Conferências Nacionais das Cidades ${ }^{1}$.

Para avaliar o conteúdo dessas entrevistas e desses documentos foi desenvolvido um código de análise documental, construído a partir do código desenvolvido no trabalho de Araújo (2013) para as agendas verde (ambiental) e marrom (urbana). Neste artigo, foram considerados os componentes da agenda marrom do trabalho de Araújo (2013), haja vista a similaridade do conteúdo dessa agenda com o conteúdo da política habitacional. Os componentes de deep e policy core do código aplicado à agenda marrom foram ajustados e complementados de acordo com os temas de habitação, por meio de leitura prévia e conversas com especialistas que atuam em política urbana.

Após o desenvolvimento do código, foi realizada a codificação dos documentos e das entrevistas. Foram relacionados os trechos de textos e discursos em que os atores demonstram suas opiniões e travam embates. Esses trechos foram agrupados em categorias definidas previamente, de acordo com características relevantes de análise. A codificação correspondeu ao agrupamento dessas categorias predefinidas, pois apresentam características de interesse do subsistema de análise. Para viabilizar a codificação foi utilizado o software de apoio à análise qualitativa NVivo 11, da QSR International. Por fim, as coalizões foram identificadas por meio da classificação dos diálogos e dos posicionamentos dos atores.

\section{As políticas públicas e seus processos de concepção, diferenças e interesses: Sistema Nacional de Habitação de Interesse Social e Programa Minha Casa, Minha Vida}

\section{Sistema Nacional de Habitação de Interesse Social (SNHIS)}

O SNHIS surgiu de um projeto de lei de iniciativa popular apresentado ao Congresso Nacional em 1992, com mais de um milhão de assinaturas, as quais foram recolhidas com o apoio das Comunidades Eclesiais de Base, ligadas, principalmente, à igreja católica. Esse foi um dos quatro projetos de iniciativa popular que se tornou lei desde que a Constituição de 1988 reservou ao povo brasileiro a prerrogativa

\footnotetext{
${ }^{1}$ Luiz Philippe Torelly, ex-superintendente da CEF; Benny Schvarsberg, ex-diretor na Secretaria Nacional de Planejamento Urbano do Ministério das Cidades e professor da Universidade de Brasília; Miguel Lobato, coordenador do Movimento Nacional de Luta por Moradia; e Elcio Sigolo, representante da Câmara Brasileira da Indústria da Construção (CBIC).
} 
de propor novas leis. Como a Câmara dos Deputados não teria condições de verificar a autenticidade de todas as assinaturas, o referido projeto de lei foi atestado pelo Deputado Nilmário Miranda.

Esse projeto de lei de iniciativa popular foi elaborado com o auxílio do Fórum Nacional de Reforma Urbana, com o objetivo de criar um fundo público para o atendimento das demandas por moradia popular. Essa iniciativa surgiu na era Collor como uma ação propositiva de entidades da sociedade civil organizada. Entre os principais grupos de atores envolvidos é possível citar a Confederação Nacional das Associações de Moradores, a Central de Movimentos Populares, a União Nacional por Moradia Popular e o Movimento Nacional de Luta por Moradia (Saule \& Uzzo, 2009).

A ementa original do Projeto de Lei no 2.710, de 1992, estabelecia a criação do Fundo Nacional de Moradia Popular e o Conselho Nacional de Moradia Popular, além de outras providências. A redação final propôs alterações ao projeto, e a nova ementa passou a dispor sobre o Sistema Nacional de Habitação de Interesse Social, a criação do Fundo Nacional de Habitação de Interesse Social (FNHIS) e seu conselho gestor. Após 13 anos de tramitação e muitos embates ideológicos, a Lei no 11.124, de 16 de junho de 2005, foi sancionada e publicada no Diário Oficial da União (DOU).

A referida lei prevê um processo participativo de elaboração do Plano Nacional de Habitação e a constituição de fundos articulados nos diferentes níveis da federação, controlados por conselhos com participação popular e com ações planejadas em Planos Locais de Habitação de Interesse Social. Tais planos apresentam caráter obrigatório para entes federados dispostos a participar do sistema e interessados em receber recursos federais. Nesses planos devem constar as necessidades habitacionais de cada município e as estratégias para enfrentar o déficit habitacional (Amore, 2015).

A articulação dos três entes federados, coordenados por meio do Ministério das Cidades, foi uma proposta que surgiu no Projeto Moradia, em 2000. No âmbito desse projeto ocorreram reuniões técnicas e seminários com movimentos sociais, empresários, acadêmicos, organizações não governamentais, sindicatos e poder público para discutir a Política Nacional de Habitação (PNH). Os principais eixos da PNH foram a política fundiária, a política financeira e a estrutura institucional (Maricato, 2006).

Ademais, também foram previstos mecanismos de controle social exercidos por meio do Conselho Nacional das Cidades e dos Conselhos Estaduais e Municipais, com atribuição de gerir fundos de habitação com recursos orçamentários para subsidiar a baixa renda. Dessa maneira, para viabilizar o acesso à moradia para a população de baixa renda era necessária a aprovação do projeto de lei de iniciativa popular de criação do SNHIS e FNHIS, que tramitava há 13 anos no Congresso Nacional (Bonduki, 2009).

Na estrutura financeira do SNHIS foi previsto o equilíbrio entre as ações do Estado e do mercado. 0 primeiro se encarregou das ações de habitação de interesse social, enquanto o segundo, das ações de habitação de mercado e atendimento da demanda habitacional para ampliar a oferta à classe média (Azevedo, 2007). Portanto, a lei buscou estabelecer mecanismo de longo alcance, por meio da integração das atividades estatais e mercantis.

Assim, foram propostos dois subsistemas que tratam de forma distinta a habitação de interesse social e a habitação de mercado. Os subsistemas regulam o acesso à habitação para os que precisam de subsídio separadamente daqueles que não precisam. A separação repercute nas fontes de financiamento destinadas a cada subsistema. Para a sustentação dos subsídios necessários ao subsistema de habitação de interesse social foram reservados o Fundo de Garantia por Tempo de Serviço (FGTS) e o FNHIS, além de recursos provenientes do Fundo de Arrendamento Residencial (FAR), do Fundo de Amparo ao Trabalhador (FAT) e do Fundo de Desenvolvimento Social (FDS), ou seja, recursos públicos ou geridos pelo poder público. Já o subsistema de mercado se sustenta por meio da captação de recursos disponíveis no mercado de investimento, seja por meio das cadernetas de poupança, seja por meio de outros instrumentos, como os títulos securitizados lastreados pelos Certificados de Recebíveis Imobiliários, regulados pelo Sistema Financeiro Imobiliário (Brasil, 2004).

Dessa forma, o SNHIS buscou criar uma estrutura descentralizada de governança. Nesse sistema, a política habitacional seria executada de forma concatenada pelas instâncias federal, estadual e 
municipal, com seus respectivos fundos e conselhos de participação social. Por conseguinte, foi previsto um sistema integrado de política pública, com a inter-relação entre os planos nacional, estadual e municipal de habitação. Essas medidas visavam ampliar a cooperação entre os entes federados, buscando reduzir as sobreposições e os vazios institucionais.

Esse sistema demonstrou a preocupação de estabelecer uma política de longo prazo, integrando os diversos níveis de governo. 0 desenvolvimento de políticas voltadas a cada tipo de realidade seria realizado por meio do fortalecimento do papel dos Estados e municípios, com a participação da sociedade. Diversos grupos de atores, tais como militantes de movimentos sociais, acadêmicos e profissionais que discordavam do modelo de gestão vigente, foram instados a participar da tomada de decisão e a propor alterações nas políticas públicas.

No entanto, houve uma mudança na conjuntura política em 2005 que forçou o governo federal a negociar a ampliação da participação de partidos coligados no poder executivo. Entre as exigências feitas pela coalizão, a chefia do Ministério das Cidades era uma das prioridades. Para evitar o agravamento da crise política, o governo abdicou da proposta de desenvolvimento urbano integrado para as cidades brasileiras e o SNHIS foi continuamente enfraquecido, por meio da limitada influência dos movimentos sociais na discussão e deliberação da aplicação dos recursos do FNHIS (Maricato, 2014).

\section{Programa Minha Casa, Minha Vida (PMCMV)}

Como resposta à crise econômica mundial de 2008, que teve reflexos no crescimento econômico brasileiro, e visando à eleição que se aproximava em 2010, o governo optou pela adoção de políticas com respostas de curto prazo no que se refere ao aquecimento da economia, que incluíam a manutenção do crédito, o atendimento aos setores mais atingidos pela recessão e a sustentação dos investimentos públicos, principalmente, na área de infraestrutura.

No âmbito dessas medidas foram priorizados os investimentos na área de habitação, para que o setor da construção civil pudesse oferecer novas oportunidades de trabalho para população com baixa qualificação. No entanto, tal medida acarretou consequências relativas à qualidade dos empregos gerados. As negociações entre o governo e as construtoras, para definir o menor custo das unidades habitacionais, redundaram na precarização das relações trabalhistas e no uso sistemático da informalidade (Arantes \& Fix, 2009).

O PMCMV foi instituído em 2009, por meio da medida provisória editada em parceria com o setor imobiliário e o setor da construção civil (Amore, 2015). A Medida Provisória no 459/2009 recebeu mais de 300 emendas e tramitou nas duas casas do Congresso Nacional em caráter de urgência, sendo aprovada em menos de quatro meses e remetida à sanção presidencial em junho. No mês subsequente foi transformada na Lei no 11.977/2009, publicada no DOU em 8 de julho de 2009.

Com o objetivo de criar condições de ampliação do mercado habitacional para atendimento às famílias com renda de até dez salários mínimos, o governo federal lançou o PMCMV e anunciou a construção de um milhão de casas, com investimento de $\mathrm{R} \$ 34$ bilhões. Estabelecendo um patamar de subsídio direto, proporcional à renda das famílias, esse programa buscou impactar a economia por meio de efeitos multiplicadores gerados pela indústria da construção. Além dos subsídios, buscava também aumentar o volume de crédito para aquisição e produção de moradias, ao mesmo tempo em que reduzia os juros com a criação do Fundo Garantidor da Habitação (Cardoso et al., 2011).

Considerando o desenho adotado para o programa, baseado na participação do setor privado, o PMCMV relegou ao segundo plano as premissas e os debates acumulados em torno do Plano Nacional de Habitação de Interesse Social. Um dos impactos mais imediatos em relação aos programas desenvolvidos no âmbito do FNHIS foi a redução dos repasses de recursos para as ações de provisão habitacional. Desde o lançamento do PMCMV, o Fundo Nacional de Habitação de Interesse Social passou a concentrar seus recursos nas ações de urbanização de assentamentos precários e desenvolvimento institucional. Os recursos foram alocados em obras complementares de projetos em andamento, 
financiados com recursos do Programa de Aceleração do Crescimento (PAC), demonstrando o caráter subsidiário do FNHIS nas decisões de política habitacional (Cardoso et al., 2011).

Como resposta à crise mundial, o governo federal buscou promover uma política de habitação com apelo social. O PMCMV institucionalizou e centralizou as políticas habitacionais antes dispersas em vários órgãos e sujeitas às descontinuidades. O Minha Casa, Minha Vida significou a criação da marca de um programa que abarca uma série de subprogramas, modalidades, fundos, linhas de financiamento, tipologias, agentes financeiros, agentes operadores e formas de acesso ao produto da casa própria (Amore, 2015).

O total de contratações nas duas fases do PMCMV correspondeu a 3,4 milhões de unidades habitacionais em cinco anos, referente ao período de 2009 a 2014, mas ainda prevalece demanda acentuada por habitação para população de baixa renda. 0 déficit é superior a 6,068 milhões de unidades, de acordo com dados do Relatório de Déficit Habitacional no Brasil 2013-2014 (Fundação João Pinheiro, 2016).

No entanto, a dinâmica do PMCMV nem sempre leva em consideração o déficit habitacional para selecionar os municípios prioritários. Ao abdicar do papel de produtor direto de habitação de interesse social, o poder público cede à iniciativa privada a relevante tarefa de decisão sobre a localização dos conjuntos habitacionais. Na lógica de mercado são priorizados os aspectos de viabilidade econômica dos empreendimentos e são desprezados os aspectos de reforma urbana e direito à cidade. Dessa forma, são relegados ao segundo plano os instrumentos de indução do desenvolvimento urbano, regularização fundiária e democratização da gestão urbana, conforme previsto no Estatuto da Cidade (Marguti \& Aragão, 2016).

\section{Semelhanças e diferenças entre as leis que instituem SNHIS e PMCMV}

A estratégia utilizada neste tópico é a comparação dos artigos da Lei no $11.124 / 2005$, referente ao Sistema Nacional de Habitação de Interesse Social, e Lei no 11.977/2009, referente ao Programa Minha Casa, Minha Vida. A finalidade é identificar semelhanças e diferenças, bem como consensos e conflitos em relação às crenças e às ideias presentes no subsistema de política pública de habitação, conforme disposto no Quadro 1.

Quadro 1 - Semelhanças e diferenças entre SNHIS e PMCMV

\begin{tabular}{|c|l|l|}
\hline Temas & \multicolumn{1}{|c|}{ Lei $\mathrm{n}^{0}$ 11.124/2005 - SNHIS } & \multicolumn{1}{|c|}{ Lei $\mathrm{n}^{\circ}$ 11.977/2009 - PMCMV } \\
\hline Direito à moradia & $\begin{array}{l}\text { Acesso à terra urbanizada para população de } \\
\text { menor renda. }\end{array}$ & $\begin{array}{l}\text { Produção e aquisição de habitações } \\
\text { para famílias com renda de até dez } \\
\text { salários mínimos. }\end{array}$ \\
\hline Subsídios & OSistema prevê subsídios. & O Programa prevê subsídios. \\
\hline Localização & Áreas inseridas na malha urbana. & $\begin{array}{l}\text { Terrenos na malha urbana ou em } \\
\text { áreas de expansão. }\end{array}$ \\
\hline Questão federativa & $\begin{array}{l}\text { Sistema descentralizado no âmbito da União, } \\
\text { Estados, Distrito Federal e municípios. }\end{array}$ & $\begin{array}{l}\text { Programa concentrado no âmbito da } \\
\text { União. }\end{array}$ \\
\hline Participação e controle social & $\begin{array}{l}\text { Previsão de conselhos nacional, estadual e } \\
\text { municipal. }\end{array}$ & Não está previsto na lei. \\
\hline $\begin{array}{c}\text { Financiamento do } \\
\text { desenvolvimento urbano }\end{array}$ & Modelo descentralizado. & Modelo centralizado. \\
\hline $\begin{array}{c}\text { Regularização fundiária } \\
\text { Recursos do FNHIS destinados a ações de } \\
\text { regularização fundiária. }\end{array}$ & $\begin{array}{l}\text { Revogado o capítulo da lei que } \\
\text { tratava de regularização fundiária. }\end{array}$ \\
\hline
\end{tabular}

Fonte: Elaboração dos autores (2017). 


\section{Análise das coalizões}

\section{Código de análise documental}

Adicionalmente à identificação dos atores, foi construído um código de análise documental organizado a partir dos principais tipos de crença política, identificados por meio de leitura exploratória e apoio ao referencial teórico do ACF. Os componentes de deep core e policy core foram desenvolvidos a partir da agenda marrom proposta por Araújo (2013). Os itens são dispostos de maneira exaustiva e mutuamente excludente para propiciar a codificação dos documentos e das entrevistas. Os componentes analisados neste artigo estão descritos nos Quadros 2 e 3.

Quadro 2 - Deep Core

\begin{tabular}{|c|c|}
\hline $\mathbf{N}^{\circ}$ & Componentes do código de análise documental - Deep Core \\
\hline $\mathrm{DCl}$ & $\begin{array}{l}\text { Visão sobre a justiça distributiva } \\
\text { 1) Baixa preocupação com a equidade } \\
\text { 2) Foco exclusivo ou priorização da equidade intrageracional } \\
\text { 3) Foco na equidade intrageracional e intergeracional } \\
\text { 4) Foco exclusivo ou priorização da equidade intergeracional }\end{array}$ \\
\hline DC2 & $\begin{array}{l}\text { Visão sobre a intervenção do Estado no meio socioeconômico } \\
\text { 1) Mecanismos de mercado são priorizados em relação à intervenção do Estado } \\
\text { 2) Mecanismos de mercado são priorizados, mas Estado intervém para regular falhas de mercado } \\
\text { 3) Intervenção do Estado é priorizada em relação ao mercado, porque as falhas são graves } \\
\text { 4) Intervenção do Estado ampla, eliminando ao máximo os mecanismos de mercado }\end{array}$ \\
\hline DC3 & $\begin{array}{l}\text { Visão sobre a relação entre governo e democracia } \\
\text { 1) Decisões efetivadas pela elite dirigente, com desconsideração da participação da sociedade civil } \\
\text { 2) Decisões efetivadas pelas autoridades competentes de forma conjunta com grupos da sociedade } \\
\text { 3) Ampla participação da sociedade nas decisões governamentais e acompanhamento da política }\end{array}$ \\
\hline DC4 & $\begin{array}{l}\text { Visão sobre o valor das políticas públicas } \\
\text { 1) Desconsideração do valor das políticas públicas } \\
\text { 2) Políticas públicas corretas são as que refletem as demandas da comunidade } \\
\text { 3) Políticas públicas corretas são as que se orientam por pressupostos, diretrizes e conceitos } \\
\text { 4) Políticas públicas corretas são as que se orientam pelos resultados, pois os fins justificam os meios }\end{array}$ \\
\hline
\end{tabular}

Fonte: Adaptado de Araújo (2013).

Quadro 3 - Policy Core

\begin{tabular}{|c|c|}
\hline $\mathbf{N}^{\circ}$ & Componentes do código de análise documental - Policy Core \\
\hline $\mathrm{PCl}$ & $\begin{array}{l}\text { Atribuições dos níveis de governo em política habitacional } \\
\text { 1) Centralização na União } \\
\text { 2) Descentralização para Estados e municípios } \\
\text { 3) Municipalização plena } \\
\text { 4) Descentralização ponderada } \\
\text { 5) Gestão articulada entre os entes federados }\end{array}$ \\
\hline PC2 & $\begin{array}{l}\text { Tipos prioritários de instrumentos de política de habitação } \\
\text { 1) Oposição aos instrumentos de política habitacional } \\
\text { 2) Instrumentos voluntários } \\
\text { 3) Instrumentos regulatórios } \\
\text { 4) Visão integrada com conciliação ao Plano Local de Habitação de Interesse Social }\end{array}$ \\
\hline PC3 & $\begin{array}{l}\text { Participação do setor privado na solução dos problemas habitacionais } \\
\text { 1) Pouca consideração } \\
\text { 2) Pode ser relevante } \\
\text { 3) Participação essencial }\end{array}$ \\
\hline PC4 & $\begin{array}{l}\text { Peculiaridades regionais e locais } \\
\text { 1) Baixa preocupação } \\
\text { 2) Nível intermediário de preocupação } \\
\text { 3) Preocupação elevada }\end{array}$ \\
\hline
\end{tabular}


Quadro 3 - Continuação...

\begin{tabular}{|c|c|}
\hline PC5 & $\begin{array}{l}\text { Atuação dos órgãos colegiados com participação de representantes da sociedade civil } \\
\text { 1) Pouca consideração } \\
\text { 2) Relevante, mas as funções são consultivas } \\
\text { 3) Essencial, com funções consultivas e deliberativas }\end{array}$ \\
\hline PC6 & $\begin{array}{l}\text { Abrangência do planejamento em áreas urbanas } \\
\text { 1) Desconsideração da relevância do planejamento urbano } \\
\text { 2) Foco em aspectos específicos de setores determinados } \\
\text { 3) Foco em determinado setor, com articulação intrasetorial } \\
\text { 4) Foco na intersetorialidade, por meio da articulação técnica e política } \\
\text { 5) Foco na intersetorialidade, por meio do gerenciamento de projetos estratégicos }\end{array}$ \\
\hline PC7 & $\begin{array}{l}\text { Plano Diretor } \\
\text { 1) Desconsideração da relevância } \\
\text { 2) Documento técnico que abrange questões urbanísticas } \\
\text { 3) Pacto político que abrange questões urbanísticas }\end{array}$ \\
\hline PC8 & $\begin{array}{l}\text { Regularização fundiária urbana } \\
\text { 1) Desconsideração da importância da regularização fundiária } \\
\text { 2) Prioridade para a regularização, mesmo nos casos de regularização de interesse específico } \\
\text { 3) Prioridade para o direito à moradia, nos casos de regularização de interesse social } \\
\text { 4) Possibilidade de regularização realizada caso a caso, com análise de aspectos sociais }\end{array}$ \\
\hline
\end{tabular}

Fonte: Adaptado de Araújo (2013).

\section{Identificação das coalizões e respectivos ideários}

Os atores e as coalizões de política habitacional foram identificados a partir da percepção quanto à capacidade de influenciar a tomada de decisão da política pública. Para subsidiar a análise foram levadas em consideração a pesquisa anterior de Araújo (2013), as entrevistas e a triangulação de documentos, tais como análise de leis e normas, notas de audiência pública, atas, resoluções e recomendações do Conselho e da Conferência das Cidades, bem como os apontamentos do Comitê Técnico de Habitação.

Foram identificados os discursos e os comportamentos dos principais atores que participaram dos processos decisórios estudados, principalmente da elaboração das leis e dos atos normativos federais. A seleção das demandas políticas expressas nas narrativas dos atores possibilitou o agrupamento de crenças em torno de coalizões de defesa, de acordo com o ACF. A constatação das crenças compartilhadas foi referenciada por meio da aplicação de código de análise documental que considerou os componentes de deep e policy core, conforme disposto nos Quadros 2 e 3, respectivamente.

Mediante análise qualitativa de codificação dos dados, foram identificadas três coalizões predominantes no subsistema de política habitacional no período de 1992 a 2014:

- Coalizão sociourbanista;

- Coalizão desenvolvimentista tradicional;

- Coalizão urbanocrata.

As principais crenças estruturadoras das coalizões e o papel que elas desempenham na formulação e na implementação da política pública de habitação são identificados no Quadro 4. Com relação ao primeiro período da pesquisa, compreendido entre o início de 1992 e o primeiro semestre de 2005, a análise das entrevistas e dos documentos utilizados na codificação evidencia a prevalência das crenças que caracterizam a coalizão sociourbanista. Nessa coalisão, a política urbana buscou refletir as demandas da comunidade, dos movimentos sociais, das entidades de classe e dos trabalhadores, como pode ser observado no discurso do Ministro das Cidades (Brasil, 2003, p. 1). 
Quadro 4 - Crenças e coalizões

\begin{tabular}{|c|c|c|c|}
\hline $\begin{array}{l}\text { Dimensões das crenças } \\
\text { de deep e policy core }\end{array}$ & Coalizão Sociourbanista & $\begin{array}{c}\text { Coalizão Desenvolvimentista } \\
\text { Tradicional }\end{array}$ & Coalizão Urbanocrata \\
\hline Justiça distributiva & $\begin{array}{l}\text { Tratamento equitativo em } \\
\text { relação às desigualdades } \\
\text { sociais. }\end{array}$ & $\begin{array}{l}\text { Baixa preocupação com a } \\
\text { equidade. }\end{array}$ & $\begin{array}{l}\text { Preocupação } \\
\text { intermediária com as } \\
\text { desigualdades sociais. }\end{array}$ \\
\hline $\begin{array}{l}\text { Intervenção do Estado no } \\
\text { meio socioeconômico }\end{array}$ & Ampla. & Estado com presença marcante. & $\begin{array}{l}\text { Estado com presença } \\
\text { marcante. }\end{array}$ \\
\hline $\begin{array}{l}\text { Relação entre governo e } \\
\text { democracia }\end{array}$ & $\begin{array}{l}\text { Participação da sociedade nas } \\
\text { decisões do governo. }\end{array}$ & $\begin{array}{l}\text { Decisões tomadas pela elite } \\
\text { dirigente. }\end{array}$ & $\begin{array}{l}\text { Decisões tomadas pela } \\
\text { elite dirigente ou } \\
\text { participação de grupos } \\
\text { selecionados. }\end{array}$ \\
\hline $\begin{array}{l}\text { Valor das políticas } \\
\text { públicas }\end{array}$ & $\begin{array}{l}\text { Políticas públicas efetivas são as } \\
\text { que refletem as demandas da } \\
\text { sociedade. }\end{array}$ & $\begin{array}{l}\text { Políticas públicas com foco nos } \\
\text { resultados. }\end{array}$ & $\begin{array}{l}\text { Políticas públicas com } \\
\text { foco nos resultados. }\end{array}$ \\
\hline $\begin{array}{l}\text { Atribuições dos níveis de } \\
\text { governo }\end{array}$ & Valorização das esferas locais. & Centralização na União. & Centralização na União. \\
\hline $\begin{array}{l}\text { Instrumentos de política } \\
\text { habitacional }\end{array}$ & $\begin{array}{l}\text { Valoriza o Plano Local de } \\
\text { Habitação de Interesse Social. }\end{array}$ & $\begin{array}{l}\text { Instrumentos não devem } \\
\text { atrapalhar o crescimento } \\
\text { econômico, concepção de } \\
\text { habitação em larga escala. }\end{array}$ & $\begin{array}{l}\text { Instrumentos não } \\
\text { devem impedir o } \\
\text { crescimento. }\end{array}$ \\
\hline $\begin{array}{l}\text { Participação do setor } \\
\text { privado }\end{array}$ & $\begin{array}{l}\text { Pouca participação, maior } \\
\text { atuação do Estado. }\end{array}$ & Ampla. & Pouca consideração. \\
\hline $\begin{array}{l}\text { Peculiaridades regionais e } \\
\text { locais }\end{array}$ & $\begin{array}{l}\text { Preocupação elevada com as } \\
\text { características regionais e locais. }\end{array}$ & Pouca consideração. & $\begin{array}{l}\text { Nível intermediário de } \\
\text { preocupação sobre o } \\
\text { tema. }\end{array}$ \\
\hline $\begin{array}{l}\text { Órgãos colegiados com } \\
\text { participação social }\end{array}$ & $\begin{array}{l}\text { Valorização de conselhos e } \\
\text { conferências das cidades. }\end{array}$ & $\begin{array}{l}\text { Pouca importância ou função } \\
\text { meramente consultiva do } \\
\text { conselho para respaldar a } \\
\text { decisão da elite dirigente. }\end{array}$ & $\begin{array}{l}\text { Pouca consideração ou } \\
\text { aceitação com funções } \\
\text { consultivas. }\end{array}$ \\
\hline $\begin{array}{l}\text { Abrangência do } \\
\text { planejamento em áreas } \\
\text { urbanas }\end{array}$ & $\begin{array}{l}\text { Planejamento integrado é } \\
\text { essencial, mas há dificuldade } \\
\text { para chegar à } \\
\text { intersetorialidade. }\end{array}$ & $\begin{array}{l}\text { Foco no setor de habitação, sem } \\
\text { visão integrada de política } \\
\text { urbana. }\end{array}$ & $\begin{array}{l}\text { Foco em aspectos } \\
\text { específicos do } \\
\text { planejamento ou } \\
\text { setores determinados. }\end{array}$ \\
\hline Plano Diretor & Pacto político. & Documento técnico. & Documento técnico. \\
\hline $\begin{array}{l}\text { Regularização fundiária } \\
\text { urbana }\end{array}$ & $\begin{array}{l}\text { Prioridade para o direito à } \\
\text { moradia. }\end{array}$ & $\begin{array}{l}\text { Prioridade para a regularização, } \\
\text { independente de renda. }\end{array}$ & $\begin{array}{l}\text { Prioridade para a } \\
\text { regularização, } \\
\text { independente de } \\
\text { renda. }\end{array}$ \\
\hline
\end{tabular}

Fonte: Elaboração dos autores (2017).

O texto base da Conferência Nacional das Cidades é o resultado da experiência acumulada pela sociedade civil e pelos profissionais que se engajaram nas lutas urbanas das últimas décadas. Trata-se de um primeiro passo para estimular o debate e as contribuições, as quais permitirão a construção coletiva da política de desenvolvimento urbano do país, que requer tempo e empenho, bem como o respeito à diversidade de opiniões (Apresentação do Ministro Olívio Dutra, constante no texto base da primeira Conferência Nacional das Cidades, realizada em 2003).

Os atores identificados na coalizão sociourbanista compartilham crenças acerca da defesa da reforma urbana, reconhecimento do direito à moradia para população de baixa renda, importância do controle social para tomada de decisões democráticas e redução das desigualdades socioespaciais. Nesse período, os atores coletivos com maior destaque foram os movimentos sociais de luta por moradia, organizações não governamentais, como o Instituto Pólis, entidades acadêmicas, profissionais e de pesquisa, como o Instituto dos Arquitetos do Brasil, e membros do Fórum Nacional de Reforma Urbana.

Tais atores se envolveram nas discussões sobre a ênfase na moradia como direito social a ser assegurado pelo Estado. Essa coalizão contribuiu com mudanças institucionais relacionadas à inclusão dos artigos de política urbana na Constituição Federal de 1988, aprovação do Estatuto da Cidade, criação do SNHIS e do FNHIS. Além disso, eles se engajaram na luta pela ampliação de 
mecanismos de participação e controle social, tais como institucionalização do Conselho e das Conferências das Cidades.

No entanto, em 2005, houve mudança na conjuntura política que forçou o governo federal a renegociar a ampliação da participação de partidos coligados no poder executivo. Para evitar o agravamento da crise política e constituir maioria no Congresso Nacional, o governo aceitou substituir o ministro Olívio Dutra, representante do Partido dos Trabalhadores, por Marcio Fortes, representante do Partido Progressista. As trocas enfraqueceram a influência dos movimentos sociais e exacerbaram a influência dos setores empresariais. A questão da moradia transformou-se em recurso de barganha política, tratada como mercadoria a ser negociada pela iniciativa privada. De acordo com Raquel Rolnik (2009, p. 35):

[...] a área de desenvolvimento urbano no Brasil é profundamente afetada pela lógica política tradicional, fortemente estruturada no clientelismo, patronagem e controle por coalizões de interesses empresariais, reinventados no contexto urbano e metropolitano brasileiros. Para entendê-la é necessário analisar onde e como se dão os processos decisórios reais sobre os investimentos urbanos e sua relação com o sistema político e modelo federativo no país.

Dessa maneira, a gestão política subsequente enfatizou a implementação do PMCMV no período de 2009 a 2011. Por meio das entrevistas e dos documentos utilizados na codificação, foi possível evidenciar o enfraquecimento da coalizão urbanocrata e a prevalência das crenças que caracterizaram a coalizão desenvolvimentista tradicional. Esse período foi marcado por reduzida consideração ao princípio de equidade e aos aspectos socioambientais. A visão sobre os recursos naturais foi o utilitarismo puro, com construção de empreendimentos habitacionais em larga escala. As atividades econômicas assumiram papel relevante, mas a discussão sobre a reforma urbana perdeu força e importância política. Assim, o Estado assumiu presença marcante para incentivar a iniciativa privada e o crescimento econômico, principalmente por meio de política anticíclica para aquecer a economia e gerar novos empregos. A tomada de decisão e o financiamento da política de desenvolvimento urbano foram ações centralizadas no âmbito do governo federal, que detinha o orçamento do PAC e do PMCMV. A política urbana foi pautada pela atuação do setor privado, que priorizou os benefícios econômicos em detrimento da distribuição de renda e da redução das desigualdades sociais, como pode ser observado no discurso de Celso Petrucci (chefe do Sindicato Imobiliário de São Paulo): “A valorização imobiliária é consequência do desenvolvimento" (Maricato, 2014, p. 79).

Nesse período prevaleceu o foco nos resultados, com políticas públicas voltadas ao mercado. Sendo assim, a preocupação com os interesses financeiros foi maior do que a preocupação com os interesses locais e regionais. A ênfase recaiu na atuação do setor privado e os principais representantes dessa coalizão foram os empresários ligados à Câmara Brasileira da Indústria da Construção (CBIC), atores que mantinham estreita ligação com a Presidência da República.

No entanto, foram identificados diversos problemas decorrentes do Programa Minha Casa, Minha Vida, tais como falta de articulação com a política de desenvolvimento urbano, ausência de mecanismos para enfrentar a questão fundiária, problemas de localização dos empreendimentos, privilégios concedidos aos empresários, empreendimentos habitacionais concebidos em larga escala, além de baixa qualidade arquitetônica e construtiva dos conjuntos habitacionais. Ademais, foi possível observar descontinuidade em relação ao SNHIS e pouca ênfase aos processos de participação e controle social (Cardoso \& Aragão, 2013).

Para tentar corrigir esses problemas, os atores do Ministério das Cidades, da Caixa Econômica Federal e do Conselho Empresarial Brasileiro para o Desenvolvimento Sustentável (CEBDS) buscaram intervir na concepção de regras da política habitacional. Assim, o período de 2011 a 2014, relacionado à segunda fase do PMCMV, evidenciou a prevalência das crenças que caracterizaram a coalizão urbanocrata. Esse período foi marcado por melhorias incrementais no Programa Minha Casa, Minha Vida. Tais mudanças institucionais foram melhorias pontuais que não impactaram no escopo do programa e não alteraram os benefícios concedidos ao setor privado na condução da política pública. A coalizão urbanocrata distinguese da coalizão desenvolvimentista tradicional devido às preocupações com aspectos de sustentabilidade 
ambiental e com a qualidade de vida da população que reside nas cidades brasileiras, como pode ser observado na institucionalização do artigo 2o da Lei no 12.424, de 2011.

Os empreendimentos do PMCMV devem observar adequação ambiental do projeto, bem como a infraestrutura básica que inclua vias de acesso, iluminação pública e solução de esgotamento sanitário e de drenagem de águas pluviais (Brasil, 2011, p. 8-9).

A preocupação com a sustentabilidade está presente no âmbito social, econômico e ambiental, bem como no combate às desigualdades social, racial e de gênero. Dessa forma, essa coalizão propiciou mudanças institucionais relacionadas à elaboração de normativos do PMCMV, que passaram a prever prioridades para famílias chefiadas por mulheres, idosos, pessoas com deficiência e residentes em áreas de risco e regiões insalubres. Quanto à infraestrutura básica, passou a ser necessário incluir vias de acesso, iluminação pública e solução de esgotamento sanitário e de drenagem de águas pluviais, bem como permitir ligações domiciliares de abastecimento de água e energia elétrica. Além disso, o poder público local passou a firmar compromisso de instalação ou de ampliação dos equipamentos e serviços relacionados à educação, à saúde, ao lazer e ao transporte público.

No entanto, essas mudanças institucionais incrementais não foram suficientes para desenvolver uma política habitacional baseada na gestão democrática e no direito à cidade para todos os cidadãos. 0 interesse de mercado continua a se sobrepor ao interesse público, dificultando o enfrentamento da questão fundiária. Tais características representam entraves à concepção da função social da propriedade e dificultam a implementação de uma efetiva política de desenvolvimento urbano integrada.

\section{Considerações finais}

Este artigo realizou uma análise do subsistema de política habitacional no Brasil, no período de 1992 a 2014, levando em consideração o referencial teórico do Advocacy Coalition Framework. As principais bases regulatórias da pesquisa foram as Leis que instituíram o Sistema Nacional de Habitação de Interesse Social e o Programa Minha Casa, Minha Vida. Nesse interim, foram abordados os processos decisórios e as mudanças institucionais que ocorreram em tal período. Os objetos de pesquisa analisados foram os processos de mudança institucional, com ênfase nos valores e nas ideias que contribuem para a constituição do sistema de crenças sociais e políticas, socializando os atores em torno de padrões de comportamento, com relações permeadas por conflitos e alianças.

Para responder às perguntas de pesquisa sobre quais são as coalizões que influenciam a dinâmica da política de habitação e como essas coalizões atuam e propiciam mudanças institucionais, foram analisados os atores que participaram da política de habitação e da política urbana brasileira. As análises foram pautadas por entrevistas e um conjunto de documentos codificados por meio do desenvolvimento de um código de análise documental, com componentes de deep e policy core. Segundo o ACF, o deep core corresponde aos axiomas fundamentais, com postulados normativos e ontológicos. Já o policy core corresponde às posições básicas sobre a política pública, concernentes às estratégias para atingir os valores de deep core.

No esforço de codificação dos componentes do código de análise documental, foi possível constatar que a Constituição de 1988 e o Estatuto da Cidade delegaram aos municípios a competência para definir e implementar os mecanismos de política urbana, principalmente os princípios de função social da propriedade e controle do uso do solo. No entanto, a descentralização prevista na Carta Magna gera impasse em relação à articulação entre a esfera federal, que detém recursos a serem aplicados na política de habitação, e a esfera municipal, que detém o domínio das terras públicas e está incumbida de realizar a política urbana. Esse modelo de distribuição de competências não confere papel específico aos Estados, sendo assim, ficam à margem do processo de distribuição de recursos entre esferas e praticam sua própria política habitacional. É possível verificar em alguns Estados a criação de Secretarias de Políticas Habitacionais, tal como é o caso, entre outros, de São Paulo, com a Companhia de Desenvolvimento Habitacional e Urbano (CDHU). 
Nas análises realizadas na pesquisa foi possível observar que o Programa Minha Casa, Minha Vida foi criado com finalidade de gerar demanda habitacional e impulsionar o mercado financeiro, sem propor solução para o problema da segregação socioespacial e da questão da terra, que representam entraves da política urbana brasileira. Já o SNHIS foi formulado com o intuito de ser uma política que buscava discutir a reforma urbana e o direito à cidade, com diretrizes urbanas consolidadas, participação social e distribuição de competências entre os entes federados, mas não chegou a ser implementado na prática. Cada um desses períodos foi marcado por intensas relações de poder entre diferentes grupos de atores, que foram mapeados e analisados por meio de coalizões de defesa. Além disso, a análise constatou também que a contribuição do PMCMV para reduzir o déficit habitacional no nível nacional se mostrou limitada, devido à expansão da demanda no mesmo período. No entanto, se o número de unidades habitacionais entregues pelo programa não resultou em redução efetiva do déficit, pelo menos foi suficiente para conter seu avanço.

Uma última consideração relevante é o fato de o PMCMV ser um programa pragmático e capaz de gerar retornos políticos imediatos, muito mais que o SNHIS. Entretanto, o PMCMV é uma mudança institucional baseada no que se chama em Ciência Política de Garbage Can (March \& Olsen, 1984), visto que retorna à "fórmula" do Banco Nacional de Habitação estendida às faixas pobres da população, que consiste na construção de habitações padronizadas, de baixo custo financeiro e de baixa qualidade construtiva.

A prioridade de aplicação de recursos no Programa Minha Casa, Minha Vida faz parte de uma estratégia de introduzir mecanismos de mercado na gestão das políticas de desenvolvimento urbano. No entanto, a redução da política ao discurso financeiro resulta em uma financeirização da política de habitação, acarretando prejuízo em relação à universalização do acesso à moradia (Royer, 2009). Dessa maneira, o aquecimento do mercado proveniente da explosão nos preços dos imóveis no território brasileiro reafirma a segregação e amplia as desigualdades sociais.

\section{Referências}

Amore, C. (2015). Minha Casa Minha Vida para iniciantes. In C. Amore, L. Shimbo, \& M. Rufino (Eds.), Minha casa... e a cidade? Avaliação do Programa Minha Casa Minha Vida em seis estados brasileiros (pp. 11-27). Rio de Janeiro: Letra Capital.

Arantes, P., \& Fix, M. (2009). Como o governo Lula pretende resolver o problema da habitação: alguns comentários sobre o pacote habitacional Minha Casa, Minha Vida. Correio da Cidadania. Recuperado em 19 de junho de 2017, de http://www.correiocidadania.com.br/index.php?option=com_content\&view=category\&layout=blog\&id=66\&Itemi $\mathrm{d}=171$

Araújo, S. M. V. G. (2013). Política ambiental no Brasil no período 1992-2012: um estudo comparado das agendas verde e marrom (Tese de doutorado). Instituto de Ciência Política, Universidade de Brasília, Brasília.

Azevedo, S. (2007). Desafios da habitação popular no Brasil: políticas recentes e tendências. In A. Cardoso (Ed.), Habitação social nas metrópoles brasileiras: uma avaliação das políticas habitacionais em Belém, Belo Horizonte, Porto Alegre, Recife, Rio de Janeiro e São Paulo no final do século XX (pp. 12-41). Porto Alegre: Associação Nacional de Tecnologia do Ambiente Construído.

Azevedo, S., \& Andrade, L. A. G. (2011). Habitação e poder: da Fundação da Casa Popular ao Banco Nacional de Habitação. Rio de Janeiro: Centro Edelstein de Pesquisas Sociais. http://dx.doi.org/10.7476/9788579820557.

Bonduki, N. (2009). Do projeto moradia ao programa minha casa, minha vida. Teoria e Debate, 82, 8-14.

Brasil. (2003). $1^{a}$ Conferência das Cidades. Brasília: Ministério das Cidades. Recuperado em 19 de junho de 2017, de http://www.cidades.gov.br/images/stories/ArquivosSNPU/ArquivosPDF/Texto_Base_da_1_Conferencia_Nacional _das_Cidades.pdf

Brasil. (2004). Política Nacional de Habitação (Caderno Mcidades, No. 4). Brasília: Ministério das Cidades. 
Brasil. (2011, 17 de junho). Lei no 12.424, de 16 de junho de 2011. Altera a Lei $n^{\circ}$ 11.977, de 7 de julho de 2009, que dispõe sobre o Programa Minha Casa, Minha Vida (PMCMV) e dá outras providências. Brasília: Diário Oficial da União.

Capelari, M., Araújo, S., \& Calmon, P. (2015). Advocacy Coalition Framework: um balanço das pesquisas nacionais. Administração Pública e Gestão Social, 7(2), 91-99.

Cardoso, A. L., \& Aragão, T. A. (2013). Do fim do BNH ao Programa Minha Casa Minha Vida: 25 anos da política habitacional no Brasil. In A. L. Cardoso (Ed.), O Programa Minha Casa Minha Vida e seus efeitos territoriais (1. ed., pp. 17-65). Rio de Janeiro: Letra Capital.

Cardoso, A. L., Aragão, T. A., \& Araújo, F. S. (2011). Habitação de interesse social: política ou mercado? Reflexos sobre a construção do espaço metropolitano. In Anais do XIV Encontro Nacional da ANPUR (pp. 14). Rio de Janeiro: ANPUR.

Fundação João Pinheiro. Centro de Estatística e Informações. (2016). Déficit habitacional no Brasil 2013-2014. Belo Horizonte.

March, J., \& Olsen, J. (1984). The New Institutionalism: organizational factors in political life. The American Political Science Review, 78(3), 734-749. http://dx.doi.org/10.2307/1961840.

Marguti, B., \& Aragão, T. (2016). Habitação e assentamentos precários no Brasil: trajetória e desafios para o alcance da justiça espacial. In M. A. Costa (Ed.), O Estatuto da Cidade e a Habitat III: um balanço de quinze anos da política urbana no Brasil e a nova agenda urbana (pp. 325-343). Brasília: IPEA.

Maricato, E. (2006). O Ministério das Cidades e a política nacional de desenvolvimento urbano. Políticas Sociais, 12, 211-220.

Maricato, E. (2009). Por um novo enfoque teórico na pesquisa sobre habitação. Cadernos Metrópole, 21, 33-52.

Maricato, E. (2014). O impasse da política urbana no Brasil (3. ed.). Petrópolis: Vozes.

Rolnik, R. (2009). Democracia no fio da navalha: limites e possibilidades para a implementação de uma agenda de reforma urbana no Brasil. Revista Brasileira de Estudos Urbanos e Regionais, 11(2), 31-50.

http://dx.doi.org/10.22296/2317-1529.2009v11n2p31.

Royer, L. (2009) Financeirização da Política Habitacional: limites e perspectivas (Tese de doutorado). Faculdade de Arquitetura e Urbanismo, Universidade de São Paulo, São Paulo.

Sabatier, P., \& Jenkins-Smith, H. (1999). The advocacy coalition framework: an assessment. In P. A. Sabatier (Ed.), Theories of the policy process (pp. 117-166). Boulder: Westview Press.

Sabatier, P., \& Weible, C. (2007). The advocacy coalition framework: innovations and clarifications. In P. A. Sabatier (Ed.), Theories of the policy process (2nd ed., pp. 189-220). Boulder: Westview Press.

Saule, N., Jr., \& Uzzo, K. (2009). A trajetória da reforma urbana no Brasil. Chile: dph. Recuperado em 19 de junho de 2017, de http://base.d-p-h.info/pt/fiches/dph/fiche-dph-8583.html

Vicente, V., \& Calmon, P. (2011). A análise de políticas públicas na perspectiva do modelo de coalizões de defesa. In Anais do XXXV Encontro da ANPAD. Rio de Janeiro: EnANPAD.

Editor: Rodrigo Firmino

Recebido: Jan. 17, 2018

Aprovado: Jun. 25, 2018 